\title{
24-year follow-up on a patient with a Blalock-Taussig anastomosis at 23 months
} Helen B. Taussig (Honorary Associate Consultant Cardiologist at Guy's Hospital, 1948)

From the Department of Pediatrics of the Fohns Hopkins University and the

- Children's Medical and Surgical Center of the Johns Hopkins Hospital, Baltimore, Maryland, U.S.A.

2

$-$

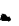

This report concerns the first 26 years in the life of a young man who had a subclavian pulmonary

'Blalock-Taussig anastomosis at 23 months of age.

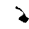

Case report (R.D.J.H.H. No. 410778)

When first seen at $2 \mathrm{I}$ months of age, in November

- 1946, the chief complaint was dyspnoea and cyanosis which were severe by 20 months of age.

- The family history was non-contributory.

Past history and present illness The patient

A was born at full term on 13 March 1945 . He

- appeared entirely normal at birth, but his cry was weak. No murmur was heard until 5 months of age when he developed cyanosis on crying;

- he was referred to a paediatrician who did hear a murmur. The cyanosis gradually became persistent.

His development was slow. He did not begin - teething until Io months of age. He sat alone at

d 14 months and stood with support at 15 months. When he began to crawl at 17 months, dyspnoea became apparent. He walked with support at 20 months. He had no attacks of paroxysmal dyspnoea or loss of consciousness but when tired he

- assumed a knee-chest position.

- Physical examination Temperature $37^{\circ} \mathrm{C}$, weight $12.7 \mathrm{~kg}$; pulse $140 /$ minute; respirations $36 /$ minute; blood pressure $96 / 70 \mathrm{mmHg}$.

The infant appeared well nourished and well

- developed but very dyspnoeic and fretful. His lips were slightly cyanotic. The eyes showed mild

suffusion. Examination revealed a small heart; a thrill was palpable over the praecordium, and a

- loud blowing systolic murmur was best heard along the left sternal border and in the inter-

- scapular region. The liver was palpable at the costal margin. The femoral arteries were readily

palpable. The extremities showed moderate cyanosis but no oedema.

Electrocardiogram ${ }^{1}$ showed normal sinus mechanism; rate I50; PR 0. I2 sec; QRS 0.06 sec.

- Right axis deviation and the unipolar praecordial leads showed right ventricular hypertrophy.

- Laboratory data Red blood count 6.95 million/ - $\mathrm{mm}^{3} ; \mathrm{Hb}$ I8 g, arterial $\mathrm{O}_{2}$ content was II·2 vol.

- 1 Unfortunately the electrocardiogram is not available for reproduction.

per cent, the capacity was $25.8 \mathrm{vol}$. per cent, and saturation was 43.4 per cent.

On fluoroscopy the heart was normal in size with a concavity in the region of the pulmonary conus. In the left anterior oblique position, the pulmonary window was very clear. No expansile pulsations were seen in the lung fields. Barium swallow showed a right aortic arch. $X$-ray confirmed the fluoroscopic finding (see Fig. I).

Diagnosis Tetralogy of Fallot with a right aortic arch.

Clinical course Two months later the patient returned to the Johns Hopkins Hospital for an operation. On 23 January 1947, Dr. William Longmire performed a left subclavian pulmonary end-to-side anastomosis. On releasing the clamps there was brisk bleeding, controlled by holding gelfoam beneath the anastomosis. A good thrill was felt in the pulmonary artery. The pulmonary artery was noted to be constricted at the midportion of the anastomosis; nevertheless, blood seemed to flow from the subclavian artery to both the right and the left lung. The infant made an uneventful recovery.

At the time of discharge he could walk without support and showed no dyspnoea and no cyanosis. His heart was slightly enlarged and a good continuous murmur was audible over the upper left chest anteriorly and posteriorly. His compensation was excellent.

Laboratory examination (II February 1947): red blood count $4.95 \mathrm{million} / \mathrm{mm}^{3}, \mathrm{Hb} 13.4 \mathrm{~g}$, haematocrit $4 \mathrm{I} \cdot 4$ per cent; arterial $\mathrm{O}_{2}$ content 13. I vol. per cent; capacity I9.9 vol. per cent, and arterial $\mathrm{O}_{2}$ saturation 65.8 per cent.

First postoperative examination was 6 months later, i.e. at $2 \frac{1}{2}$ years of age. The child was doing well. He could walk ro blocks and could go up and down stairs with help. His fingers became cyanotic only on exertion.

Physical examination: temperature $37.5^{\circ} \mathrm{C}$, height $83.7 \mathrm{~cm}$, weight $12.1 \mathrm{~kg}$, pulse $1 \mathrm{ro} / \mathrm{min}$, respirations $20 / \mathrm{min}$, blood pressure $100 / 60$ 

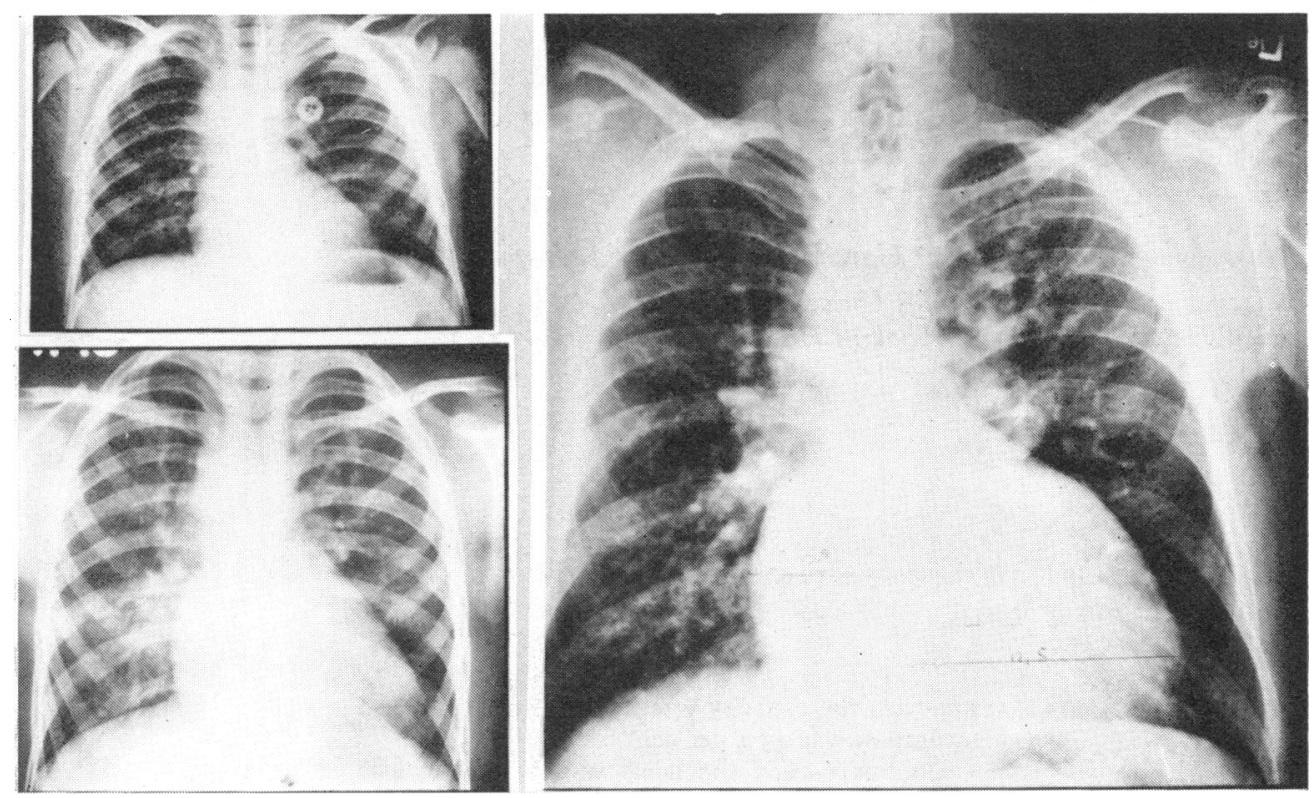

FIG. I Chest X-rays. (Top left) At 21 months (before operation); (Bottom left) at $5 \frac{1}{2}$ years; (Right) at 26 years.

mmHg. His physical finding was essentially unchanged. Fluoroscopy revealed 'a small heart and clear lungs'. Electrocardiogram remained unchanged.

He was considered to have an excellent result and was advised to return in one year.

Second postoperative examination was in October I952, at the age of $5 \frac{1}{2}$ years.

Interval history: The child had done well except for measles and mumps and an unusual number of upper respiratory infections. He had, however, had less respiratory infections than his sibs but tired slightly more easily than other children. Cyanosis was noted in cold weather or after swimming in cold water.

Physical examination (October 1952): the positive findings were limited to his heart which was enlarged. The sounds were of good quality. A harsh systolic murmur and a loud continuous murmur were readily audible.

$X$-ray and fluoroscopic examinations: the

FIG. 2 Electrocardiograms. (A)'At $5 \frac{1}{2}$ years; $(B)$ at 26 years.

(A)
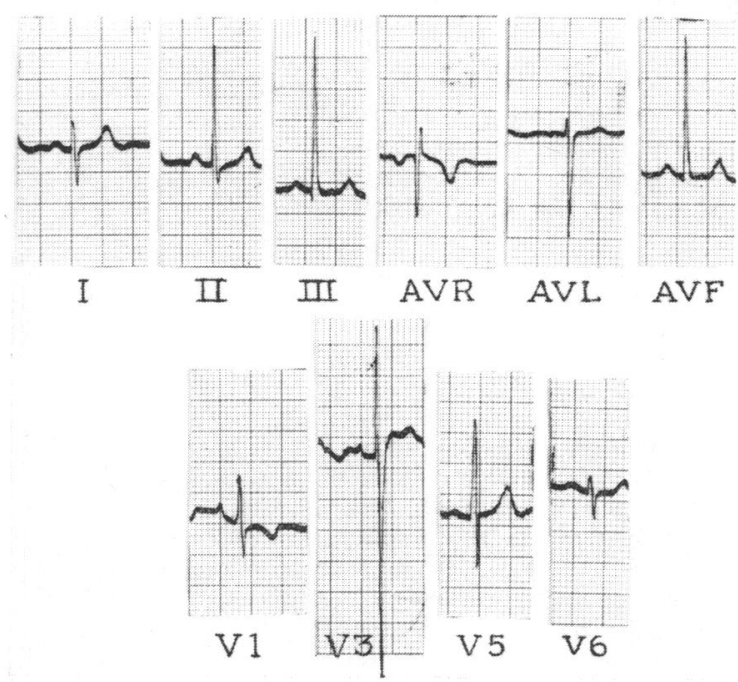

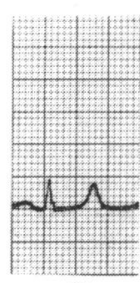

I

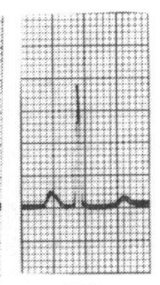

III

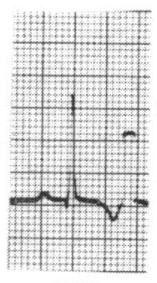

III
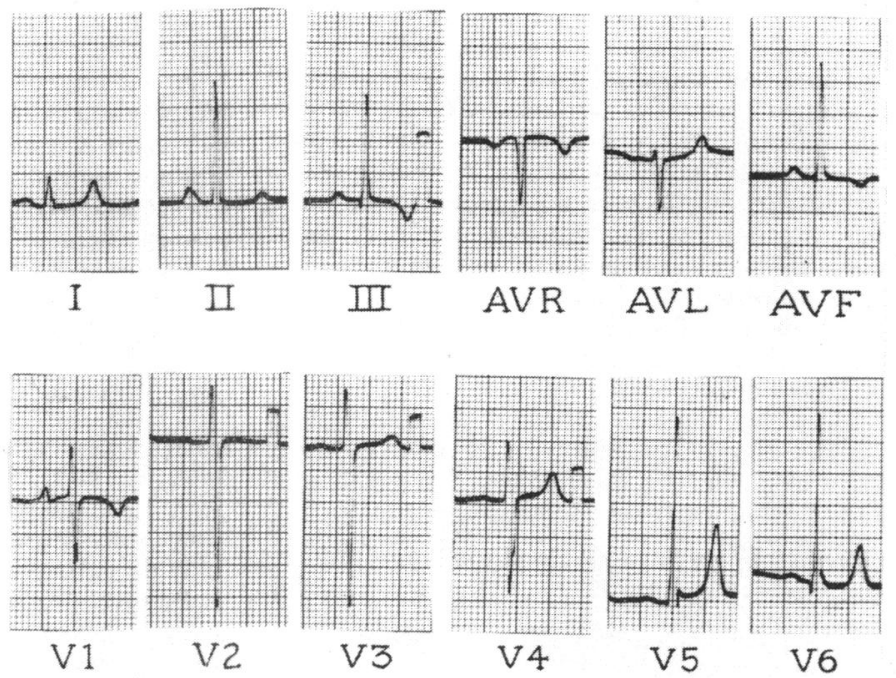
heart appeared fairly large but 'came down well on inspiration'. The hilar markings were prominent but showed no pulsations. The lung fields were well vascularized. $X$-ray confirmed the cardiac enlargement and increased pulmonary vascularity. The cardiothoracic ratio was 65 per cent (see Fig. I bottom, left).

The electrocardiogram showed right axis deviation and right ventricular hypertrophy (see Fig. 2A). The report stated that 'in comparison with the previous electrocardiogram the axis had shifted toward the left'.

The patient was given the usual instructions to receive penicillin before major or minor surgery and dental extraction. He was requested to return in two years but failed to keep his appointment.

1 Third postoperative examination was on 17 April I 971 , at 26 years of age. Interval history: his exercise tolerance was remarkably good. He experienced slight fatigue on climbing stairs and on playing basketball.

His only serious illness was a severe attack of subacute bacterial endocarditis in 1963 for which he was admitted to hospital for 6 weeks.

- He had graduated from college and was studying for a master's degree in medical biology, concentrating in the field of immunology and immunohaematology. His interest in this field had been aroused by the repeated blood samples taken during his attack of subacute bacterial endocarditis.

He married in 1969 but by choice they have had : no children.

Physical examination: temperature $36.9^{\circ} \mathrm{C}$, pulse $90 / \mathrm{min}$, respirations $24 / \mathrm{min}$, height $167 \mathrm{~cm}$, weight $76.6 \mathrm{~kg}$, blood pressure $185 / 40 \mathrm{mmHg}$.

He was a well-nourished, well-developed, slightly obese, young man. His colour was excellent. Eyes, ears, nose, and throat examination gave normal findings. The chest showed a well-healed thorac-

- otomy scar. The heart was moderately enlarged. The point of maximum impulse was in the sixth

- interspace, in the midclavicular line. A thrill was palpable along the left sternal border. A harsh 2/6

- systolic murmur was audible over the praecordium, and a systolic click was heard in the fourth left interspace. A 3/6 continuous murmur was readily heard over the left chest anteriorly and

- posteriorly, and the murmur was faintly heard posteriorly over the right chest. The liver was at

- the costal margin. The pulse pressure was wide and the dorsal pedis readily palpable. The extremities showed no clubbing and only minimal cyanosis.

Laboratory data: $\mathrm{Hb} \mathrm{I} 6.6 \mathrm{~g}$, haematocrit 45.5 per cent, oximetry reported an arterial saturation of 105 at rest, which dropped to 9I with 2 minutes of exercise.

$X$-ray examination showed that the heart was enlarged. The region of the pulmonary conus showed a concave curve. The main pulmonary arteries were not prominent but the vascularity was increased. The cardiothoracic ratio measured 58 per cent (see Fig. I right).

Electrocardiogram showed normal sinus rhythm, an axis of $75^{\circ}$. The praecordial leads revealed left ventricular hypertrophy and borderline left atrial hypertrophy (see Fig. 2B).

Final diagnosis Probable tetralogy of Fallot with moderately increased pulmonary blood flow 24 years after his first and only subclavian pulmonary end-to-side anastomosis at 23 months of age.

Comment Though the patient's heart is enlarged, it is not as large in proportion to his size as it was in 1952. Because of his extremely satisfactory condition, the patient did not wish to consider corrective operation and refused cardiac catheterization.

\section{Discussion}

Inasmuch as the patient has not consented to cardiac catheterization, the diagnosis is not proven. What else could he have? A single ventricle or a truncus arteriosus? The latter is a possibility because at the time of his original anastomosis blood appeared to be flowing to both lungs, and he does have an aortic systolic click. A systolic click is consistent with a truncus arteriosus and with pulmonary hypertension. Thus, it raises the question of whether he had pulmonary hypertension secondary to his anastomosis 24 years ago. Though his $x$-rays show evidence of excessive pulmonary blood flow, the increase in vascularity is diffuse; the main right and left pulmonary arteries are not dilated nor are the peripheral lung fields especially clear. Furthermore, the electrocardiogram now shows a left ventricular hypertrophy and the continuous murmur is loud. All these findings are against the diagnosis of pulmonary hypertension and favour the diagnosis of a tetralogy of Fallot with increased pulmonary blood flow and a normal pulmonary vascular resistance.

In summary, this patient, as an infant, suffered from a severe reduction in pulmonary blood flow. At the age of 23 months his arterial oxygen saturation was 48 per cent and his development was retarded. He was greatly helped by his first and only operation, a subclavian pulmonary end-to-side anastomosis. He has maintained his improvement for 24 years.

His only serious illness was an attack of subacute bacterial endocarditis at 18 years of age. This illness stimulated his interest in immunology and guided him into the field of medical biology. He is currently studying for a master's degree in immunohaematology.

Requests for reprints to Professor Helen B. Taussig, Department of Pediatrics, The Johns Hopkins Hospital, Baltimore, Maryland 21205, U.S.A. 